\title{
CXCR2 Antagonist QBM076
}

National Cancer Institute

\section{Source}

National Cancer Institute. CXCR2 Antagonist QBM076. NCI Thesaurus. Code C153151.

An orally available small molecule antagonist of the G protein-coupled receptor, C-X-C motif chemokine receptor 2 (CXCR2), with potential immunomodulating and antineoplastic activities. Upon administration, QBM076 binds to and inhibits the activation of CXCR2, resulting in reduced neutrophil recruitment, myeloid-derived suppressor cell (MDSC) accumulation, and may potentially slow tumorigenesis and metastatic processes. CXCR2 is upregulated in a variety of cancer types, predominately in neutrophils/MDSCs rather than tumor cells, and is thought to contribute to tumor cell proliferation, invasion, and metastasis. 